\title{
High-density lipoprotein subclasses are a potential intermediary between alcohol intake and reduced risk of cardiovascular disease: The Rancho Bernardo Study
}

\author{
Natalie D. Muth ${ }^{1,2}$, Gail A. Laughlin ${ }^{1}$, Denise von Mühlen ${ }^{1}$, Sidney C. Smith $\mathrm{Jr}^{3}$ \\ and Elizabeth Barrett-Connor ${ }^{1 *}$ \\ ${ }^{1}$ Department of Family and Preventive Medicine, University of California, San Diego, La Jolla, CA, USA \\ ${ }^{2}$ UCLA Medical Center, Los Angeles, CA, USA \\ ${ }^{3}$ UNC Center for Cardiovascular Science and Medicine, University of North Carolina, Chapel Hill, Chapel Hill, NC, USA
}

(Received 20 July 2009 - Revised 10 March 2010 - Accepted 25 March 2010 - First published online 29 April 2010)

\begin{abstract}
We conducted a cross-sectional study of NMR-derived HDL subclasses and alcohol intake among 2171 community-dwelling older adults with a large proportion of daily or near-daily alcohol consumers (44\%). We aimed to assess whether, in addition to increasing total HDL, alcohol may induce a beneficial shift in HDL particle size distribution. Participants were categorised based on reported alcohol intake (g per week) and on frequency (none, $<3$ times/week, 3-4 times/week, $\geq 5$ times/week). The association between alcohol intake and lipoprotein fractions was examined using sex-specific linear regression models adjusted for age, BMI, diabetes, current smoking, exercise and hormone therapy in women. There was a stepwise gradient with the highest weekly alcohol consumption associated with the highest total HDL size and greatest number of medium and large HDL particles, as well as higher total HDL concentrations (all $P<0 \cdot 001$ ); total small HDL did not differ. Alcohol-HDL size associations were similar in both sexes and did not differ by use of hormone replacement therapy in women. In conclusion, regular alcohol consumers had a higher number and percentage of large HDL particles than non-drinkers. These results suggest that one way that alcohol may decrease CVD is through potentially favourable changes in lipoprotein subclass composition.
\end{abstract}

Alcohol: Lipoproteins: Cholesterol: Epidemiology

CVD is the leading cause of morbidity and mortality in most of the world, despite efforts to reduce risk through effective LDL-lowering therapy ${ }^{(1,2)}$. To further reduce CVD burden, attention has expanded toward HDL as a therapeutic target. A low HDL-cholesterol (HDL-C) level is a significant independent risk factor for CVD and high HDL-C is usually cardioprotective ${ }^{(3,4)}$. While numerous efforts are underway to develop new pharmacological approaches to increase HDL levels, lifestyle interventions are also promising (for a review, see Singh et al $^{(5)}$ ).

Abundant evidence indicates that regular light or moderate alcohol consumption reduces the risk of CHD and all-cause mortality (for a review, see O'Keefe et al. ${ }^{(6)}$ ). At least half of alcohol's cardiovascular benefits are attributed to increased HDL-cholesterol ${ }^{(7)}$; HDL rises in a dose-dependent fashion with a $5 \%$ increase with one drink per $d$ and up to $12 \%$ increase with two or three drinks per d over a 3 -week time period ${ }^{(8-13)}$.

Lipoprotein subclass composition may help explain CVD risk, though few large studies have investigated the relationship between NMR-measured HDL particle size and CVD risk. Results from existing studies of HDL size and CVD risk have been mixed. Early studies suggest that high levels of large HDL confer decreased risk and high levels of small HDL increase risk $^{(8-10,14-17)}$; more recent studies have found the reverse ${ }^{(18-21)}$, with risk highest at very high levels of HDL size ${ }^{(22)}$.

We hypothesised that, in addition to increasing total HDL, regular alcohol consumption induces a favourable shift in HDL particle size, which might help explain alcohol's protective role in CVD risk. We tested this hypothesis in a crosssectional study using lipoprotein data from NMR spectroscopy to examine the quantitative association of alcohol consumption with the amount, size, and subclass proportions of HDL-C in a population of relatively healthy communitydwelling older men and women with a large proportion of daily or near-daily drinkers.

\section{Methods \\ Study population}

The Rancho Bernardo Study is a longitudinal populationbased study of healthy ageing and CVD risk factors. Study participants are mostly white and middle- to upper-middle

Abbreviations: CETP, cholesteryl ester transfer protein; HDL-C, HDL-cholesterol; HRT, hormone replacement therapy; HDL-P, HDL measured by proton NMR;

LDL-C, LDL-cholesterol.

* Corresponding author: Dr Elizabeth Barrett-Connor, fax +1 858534 8625, email ebarrettconnor@ucsd.edu 
class; all are ambulatory. At the initial visit in 1972-4, $82 \%$ of adult Rancho Bernardo residents enrolled in the study. In 1984-7, $81 \%$ (n 2480) of surviving community-dwelling participants returned for a follow-up visit at which time they completed a comprehensive questionnaire and provided a blood sample for laboratory analysis. After exclusions (age $<50$ years, current cholesterol medication, or TAG $>4000 \mathrm{mg} / \mathrm{l}), 2174$ were eligible for the present study. Of these, two were excluded for missing alcohol information and one for implausibly high reported alcohol intake, leaving a final sample of 2171. The study complies with the Declaration of Helsinki and was approved by the institutional review board of the University of California, San Diego. All study participants gave written informed consent.

\section{Alcohol consumption}

Usual alcohol consumption and weekly number of drinks of beer, wine and liquor were reported on a standardised selfadministered questionnaire. One drink was equivalent to roughly $12 \mathrm{~g}$ alcohol. Participants also were asked, 'How often do you usually consume alcoholic beverages?' with possible responses: 'never', '1 time/month', '1-2 times/ month', '1-2 times/week', '3-4 times/week' and 'almost daily or daily'. Before analysis, the less frequent categories were merged to form the following categories of alcohol frequency: none, <3 times/week, 3-4 times/week, and $5+$ times/week.

\section{Lipoprotein and lipid measurements}

Lipoprotein subclasses were determined by standard NMR spectroscopy at LipoScience, Inc. (Raleigh, NC, USA) in 1999 from plasma samples collected at the 1984-7 followup visit and stored at $-70^{\circ} \mathrm{C}$. Proton NMR spectra of freshly thawed samples $(0.25 \mathrm{ml})$ were acquired in duplicate at $47^{\circ} \mathrm{C}$ using a dedicated $400 \mathrm{MHz} \mathrm{NMR}$ analyser (LipoScience, Inc.). Lipoprotein particles of different size give rise to distinguishable lipid methyl group NMR signals, the intensities of which are proportional to the lipid mass of the particles $^{(23,24)}$. The NMR signal amplitudes were converted to mass concentration units $(\mathrm{mg} / \mathrm{l})$ of cholesterol (for LDL and HDL subclasses) or TAG (for VLDL subclasses) to allow comparison with chemically measured lipid fractions.

The NMR-determined subclasses were classified by diameter range. Diameter range was determined by calibration with purified lipoprotein subfractions isolated by ultracentrifugation and/or agarose gel filtration chromatography. For the present study we examined the HDL subclass categories: small HDL $(7 \cdot 3-8 \cdot 2 \mathrm{~nm})$, intermediate HDL $(8 \cdot 2-8.8 \mathrm{~nm})$ and large HDL $(8 \cdot 8-13 \mathrm{~nm})$. Summation of subclasses provides level of total HDL. Average HDL particle size was calculated by weighting the relative mass percentage of each subclass by its diameter. The HDL subclasses correspond to HDL subclasses by gradient gel electrophoresis as follows: large $\mathrm{HDL} \approx \mathrm{HDL}_{2 \mathrm{~b}}+\mathrm{HDL}_{2 \mathrm{a}}$; intermediate $\mathrm{HDL} \approx \mathrm{HDL}_{3 \mathrm{a}}$; small $\mathrm{HDL} \approx \mathrm{HDL}_{3 \mathrm{~b}}+\mathrm{HDL}_{3 \mathrm{c}}$.

Total fasting plasma cholesterol and TAG levels were measured by enzymic techniques using an ABA-200 biochromatic analyser in a Centers for Disease Control (CDC)certified laboratory (Abbott Laboratories, Irving, TX, USA).
HDL level was measured after precipitation of the other lipoproteins with heparin and manganese chloride. LDL levels were calculated using the Friedewald equation ${ }^{(25)}$.

\section{Other covariates}

Height, weight and waist circumference were measured in the clinic by trained nurses with participants wearing light clothing and no shoes. BMI $\left(\mathrm{kg} / \mathrm{m}^{2}\right)$ was used as an estimate of overall adiposity. Diabetes was defined by the 1999 WHO criteria: fasting blood glucose $\geq 126 \mathrm{mg} / \mathrm{dl} \quad(\geq 1260 \mathrm{mg} / \mathrm{l})$, $2 \mathrm{~h}$ post-challenge glucose level $\geq 200 \mathrm{mg} / \mathrm{dl}(\geq 2000 \mathrm{mg} / \mathrm{l})$, history of diabetes diagnosed by a physician, or treatment with an oral hypoglycaemic agent or insulin ${ }^{(26)}$. Participants self-reported their use of postmenopausal hormone replacement therapy (HRT), smoking and physical activity in a validated questionnaire. HRT and other medications were validated by a nurse who examined pills and prescriptions brought to the clinic.

\section{Statistical analyses}

Data were analysed with SPSS (version 16.0; SPSS Inc., Chicago, IL, USA). ANOVA, general linear models, and $\chi^{2}$ analysis were used for descriptive statistics across four alcohol-use groups (none, $<3$ times per week, 3-4 times per week, $5+$ times per week). Mean HDL particle sizes, subclass levels and other characteristics were compared among alcohol-use groups by univariate analysis for linear and quadratic trend. The association between alcohol consumption (both as a continuous variable and as a categorical variable based on alcohol frequency) and HDL subclasses was assessed with multiple linear regression; current HRT use in women (categorical, yes or no), BMI (as a continuous variable), diabetes (categorical, yes or no, based on 1999 WHO criteria), smoking (categorical, yes or no), exercise (categorical, moderate activity 3 or more d per week, yes or no) and age (as a continuous variable) were evaluated as covariates. Because HDL size and the intermediate and large HDL subclasses were skewed, median levels are presented for those variables. Non-parametric analyses with Kruskal-Wallis tests revealed qualitatively similar findings as parametric analyses; $P$ values are presented for parametric analysis of linear and quadratic trend only. All analyses were stratified by sex. Statistical significance was designated as $P<0 \cdot 05$.

\section{Results}

A total of 1197 women (mean age 72 years) and 974 men (mean age 73 years) participated in the present study. Overall, $8 \%$ of participants had a BMI greater than $30 \mathrm{~kg} / \mathrm{m}^{2}, 17 \%$ met Adult Treatment Panel III criteria for central obesity (waist girth $\geq 102 \mathrm{~cm}$ for men and $\geq 88 \mathrm{~cm}$ for women) and $15 \%$ had diabetes. Only $13 \%$ reported current smoking and of those approximately half smoked one pack per $\mathrm{d}$ or more; $81 \%$ reported exercising three or more times per week. Current postmenopausal HRT was reported by $27 \%$ of women; $19 \%$ were taking oestrogen alone and $8 \%$ were taking a combined oestrogen-progestin therapy.

Overall, $958(44 \%)$ participants reported drinking at least five times per week (38\% of women and $51 \%$ of men); 
$12 \%$ abstained from alcohol. Table 1 shows selected baseline characteristics of study participants across alcohol frequency categories. In both sexes, smoking behaviours and exercise frequency increased linearly with alcohol frequency while diabetes prevalence and fasting insulin levels decreased with increasing alcohol frequency. Women on HRT reported higher frequency of alcohol consumption and a corresponding significantly higher alcohol consumption in grams. BMI and waist circumference were lower among those with higher alcohol consumption in women but not men. Waist:hip ratio and creatinine levels did not differ by alcohol intake.

We assessed chemically measured TAG, total cholesterol, LDL and HDL and NMR-determined HDL subclasses including large, intermediate and small HDL and overall HDL size. The mean values of enzymically derived HDL-C $(620 \mathrm{mg} / \mathrm{l})$ and HDL measured by proton NMR (HDL-P) $(480 \mathrm{mg} / \mathrm{l})$ differed appreciably, with HDL-P approximately $21 \%$ lower than HDL-C. However, the correlation between the ascertainment methods was high $(R 0.85 ; P<0.01)$ (data not shown). Table 2 shows unadjusted levels of lipids and HDL subclasses by category of alcohol frequency. TAG levels were progressively lower as the frequency of alcohol consumption increased; however, when alcohol consumption was assessed as a continuous variable (number of drinks per week), TAG levels and alcohol consumption were negatively correlated among individuals who drank $\leq 14$ drinks per week $(R-0.051 ; P=0.033)$ and positively correlated among those who drank $>14$ drinks per week $(R 0.108 ; P=0.024)$ (data not shown). Total cholesterol levels were higher with increasing alcohol frequency in both men and women. While LDLcholesterol (LDL-C) changes were not significant for men and followed an inverted U-shaped pattern for women $(P$ quadratic $\leq 0.001)$ in that non-drinkers and daily drinkers had the lowest levels, an analysis of the LDL particle number showed that increased alcohol consumption was associated with increased particle number for both men and women $(P \leq 0 \cdot 01)$. LDL-C and HDL-C levels were modestly inversely correlated with each other for men $(R-0 \cdot 12$; $P<0.01)$ and women $(R-0.27 ; P<0.01)$. The LDL-C:HDL-C ratio decreased with increasing alcohol consumption for both sexes but this decrease was primarily due to an alcohol-related increase in HDL. Qualitative results for these analyses were similar when women were stratified by current HRT use.

Levels of each HDL measure were significantly related to alcohol frequency. Levels of HDL-C $(P<0 \cdot 001)$, large and intermediate HDL-P $(P<0.001)$, large HDL-P percentage $(P<0.001$ in women, $P=0.002$ in men), total and large HDL-P for men and women not on HRT $(P<0.001)$, large HDL-P percentage $(P<0.001$ in women, $P=0.002$ in men $)$, small HDL-P in men $(P=0.013)$, and HDL size $(P<0.001)$ were higher with increased alcohol consumption; the opposite was true for small HDL-P percentage $(P<0 \cdot 001)$. Small HDL$\mathrm{P}$ in women followed an inverted U-shaped pattern in which levels were highest for non-drinkers and for those who drank most frequently (quadratic $P<0 \cdot 001$ ). Total and large HDL-P followed a J-shaped pattern for women on HRT. Levels of HDL-C, large HDL-P and intermediate HDL-P were higher in women compared with men across all alcohol categories. Figure 1 graphically compares HDL subclass proportions by alcohol frequency, sex and current HRT.
We defined a multivariate model of various HDL subclasses as a linear function of both alcohol frequency and the number of alcoholic drinks per week (where an alcoholic drink contains $12 \mathrm{~g}$ alcohol), HRT, BMI, diabetes, smoking, exercise and age. Results were similar for both analyses. Results with alcohol as a continuous variable are shown in Table 3. Alcohol and HRT were associated with higher levels of HDL-C, medium HDL-P, large HDL-P and HDL size. While small HDL-P levels were lower among those currently using HRT and only modestly lower among those with higher levels of alcohol consumption, the percentage of small HDL-P was significantly lower with hormone use and increasing alcohol consumption $(P<0 \cdot 001)$ (data not shown). BMI, diabetes, smoking, exercise and age also influenced HDL subclasses to varying degrees, as represented by the size of $\beta$ coefficients in Table 3.

\section{Discussion}

It is known that both alcohol intake and high levels of HDL-C are associated with decreased risk of CVD (for reviews, see Singh et $a l .{ }^{(5)}$ and O'Keefe et $\left.a l .{ }^{(6)}\right)$. In the present study of relatively healthy community-dwelling older adults, of whom $44 \%$ were daily or near-daily alcohol drinkers, alcohol consumption was associated with $20 \%$ higher total HDL-C, with a higher total amount and percentage of large and medium HDL-P, and with a lower percentage of small HDL-P. These trends were identical for men and women, and independent of HRT use, itself a modulator of HDL amount and type ${ }^{(27-29)}$. The size of the alcohol-associated HDL changes reported here are equivalent to those of niacin, the current treatment of choice to raise HDL-C. Niacin raises HDL by approximately $20-30 \%{ }^{(5)}$, presumably through increases in apo A-1 production and large HDL with little effect on small $\mathrm{HDL}^{(30)}$. Consistent with previous studies, moderate alcohol consumption was associated with decreased TAG levels whereas reported consumption greater than two drinks per $\mathrm{d}$ was associated with higher TAG levels ${ }^{(6)}$.

\section{Previous research}

We are aware of five other epidemiological studies that examined the association between alcohol intake and HDL subclasses; only one of these assessed subclasses by NMR spectroscopy. The first, a cross-sectional study of 151 male and 146 female, mostly Mormon, participants found that among participants aged $\geq 18$ years, alcohol was associated with an increase in the large lipid-rich $\mathrm{HDL}_{2 b}$ in both sexes and a selective increase in intermediate-sized $\mathrm{HDL}_{3 \mathrm{a} / 2 \mathrm{a}}$ region in men only ${ }^{(31)}$. In a case-control study of 340 hospitalised patients with a myocardial infarction and an equal number of matched controls, those who reported drinking the most alcohol had higher levels of total, large $\mathrm{HDL}_{2}$ and small $\mathrm{HDL}_{3}^{(11)}$. In the third study of 279 men, participants who drank more than $5 \mathrm{~g}$ alcohol per $\mathrm{d}$ had a higher proportion of large lipid-rich $\mathrm{HDL}_{2}$ cholesterol compared with small lipid-poor $\mathrm{HDL}_{3}$ than those who drank less than $5 \mathrm{~g}$ alcohol per $\mathrm{d}^{(32)}$. These three studies used gradient gel electrophoresis to measure HDL subclasses. Among participants in the Atherosclerosis Risk in Communities (ARIC) Study, alcohol 
Table 1. Baseline characteristics of 2171 Rancho Bernardo Study participants from the 1984-7 visit with lipoprotein subclass measurements according to usual alcohol frequency (Mean values and standard deviations, medians and interquartile ranges or percentages)

\begin{tabular}{|c|c|c|c|c|c|c|c|c|c|c|c|c|c|c|c|c|c|c|}
\hline \multirow{3}{*}{$\begin{array}{l}\text { Alcohol consumption } \\
\text { (frequency per week)... }\end{array}$} & \multicolumn{9}{|c|}{ Women ( $n$ 1197) } & \multicolumn{9}{|c|}{ Men $(n 974)$} \\
\hline & \multicolumn{2}{|c|}{$\begin{array}{c}\text { None } \\
(0 \text { times/week) } \\
(n \text { 158) }\end{array}$} & \multicolumn{2}{|c|}{$\begin{array}{l}\text { Light }(<3 \\
\text { times/week) } \\
\quad(n 489)\end{array}$} & \multicolumn{2}{|c|}{$\begin{array}{c}\text { Moderate (3-4 } \\
\text { times/week) } \\
(n 93)\end{array}$} & \multicolumn{2}{|c|}{$\begin{array}{l}\text { Regular (daily) } \\
\quad(n 457)\end{array}$} & \multirow[b]{2}{*}{$P$ linear trend } & \multicolumn{2}{|c|}{$\begin{array}{c}\text { None } \\
\text { (0 times/week) } \\
(n 96)\end{array}$} & \multicolumn{2}{|c|}{$\begin{array}{l}\text { Light }(<3 \\
\text { times/week) } \\
\quad(n \text { 289) }\end{array}$} & \multicolumn{2}{|c|}{$\begin{array}{c}\text { Moderate }(3-4 \\
\text { times/week }) \\
(n 88)\end{array}$} & \multicolumn{2}{|c|}{$\begin{array}{l}\text { Regular (daily) } \\
\quad(n 501)\end{array}$} & \multirow[b]{2}{*}{$P$ linear trend } \\
\hline & Mean & SD & Mean & SD & Mean & SD & Mean & SD & & Mean & SD & Mean & SD & Mean & SD & Mean & SD & \\
\hline Age (years) & 72 & 10 & 71 & 10 & 69 & 8 & 70 & 9 & 0.013 & 71 & 11 & 71 & 10 & 70 & 10 & 72 & 9 & 0.238 \\
\hline Alcohol (g/week) & 0 & & 7 & 14 & 55 & 31 & 153 & 80 & $<0.001$ & 0 & & 11 & 19 & 61 & 31 & 190 & 115 & $<0.001$ \\
\hline Current smoker (\%) & \multicolumn{2}{|c|}{8} & \multicolumn{2}{|c|}{8} & \multicolumn{2}{|c|}{13} & \multicolumn{2}{|c|}{24} & $<0.001$ & \multicolumn{2}{|c|}{9} & \multicolumn{2}{|c|}{6} & \multicolumn{2}{|c|}{9} & \multicolumn{2}{|c|}{13} & $<0.001$ \\
\hline Former smoker (\%) & \multicolumn{2}{|c|}{3} & \multicolumn{2}{|c|}{45} & \multicolumn{2}{|c|}{54} & \multicolumn{2}{|c|}{64} & $<0.001$ & \multicolumn{2}{|c|}{56} & \multicolumn{2}{|c|}{65} & \multicolumn{2}{|c|}{64} & \multicolumn{2}{|c|}{76} & $<0.001$ \\
\hline BMI $\left(\mathrm{kg} / \mathrm{m}^{2}\right)$ & 24.5 & 4.1 & 24.5 & 3.8 & 24.2 & 3.6 & 23.7 & 3.7 & $<0.001$ & 25.4 & 3.3 & 25.9 & 3.5 & 26.2 & 3.7 & $25 \cdot 6$ & $3 \cdot 1$ & 0.677 \\
\hline $\begin{array}{l}\text { Exercise } 3+ \\
\quad \text { times/week (\%) }\end{array}$ & & & & & & & & & $<0.001$ & 8 & & & & & & & & $<0.001$ \\
\hline Diabetes (\%) & & & & & & & & & $<0.001$ & & & & & & & & & $<0.001$ \\
\hline $\begin{array}{l}\text { Hormone } \\
\text { replacement (\%) }\end{array}$ & & & & & & & & & $<0.001$ & & & & & & & & & \\
\hline Fasting insulin $(\mu \mathrm{U} / \mathrm{ml})$ & 13 & 9 & 13 & 8 & 11 & 5 & 11 & 7 & 0.001 & 14 & 9 & 16 & 14 & 14 & 8 & 13 & 8 & 0.006 \\
\hline Fasting glucose (mg/l) & 980 & 200 & 980 & 210 & 990 & 140 & 980 & 170 & 0.568 & 1030 & 220 & 1040 & 200 & 1040 & 190 & 1040 & 210 & 0.798 \\
\hline HOMA-IR* $\dagger$ & & & & & & & & & 0.008 & & & & & & & & & 0.022 \\
\hline Median & & & & & & & & & & 2 & & & & & & & & \\
\hline Interquartile range & & & & & & & & & & $2 \cdot 0$ & & & & & & & & \\
\hline SGOT $(U / /)^{\star}$ & & & & & & & & & 0.993 & & & & & & & & & 0.141 \\
\hline Median & & & & & & & & & & 2 & & & & & & & & \\
\hline Interquartile range & & & & & & & & & & 19 & & & & & & & & \\
\hline SGPT $(U /)^{*}$ & & & & & & & & & 0.404 & & & & & & & & & 0.576 \\
\hline Median & & & & & & & & & & & & & & & & & & \\
\hline Interquartile range & & & & & & & & & & 12 & & & & & & & & \\
\hline
\end{tabular}

HOMA-IR, homeostasis model of insulin resistance; SGOT, serum glutamic oxaloacetic transaminase; SGPT, serum glutamic pyruvic transaminase.

*Asymmetric variables log-transformed for analysis.

† HOMA-IR available in a subset of 1552 men and women. 
Table 2. Lipids and HDL subclasses by usual alcohol frequency in men and women

(Mean values and standard deviations, medians and interquartile ranges or percentages)

\begin{tabular}{|c|c|c|c|c|c|c|c|c|c|c|c|c|c|c|c|c|c|c|c|c|}
\hline \multirow{3}{*}{$\begin{array}{l}\text { Alcohol consumption } \\
\text { (frequency per week)... }\end{array}$} & \multicolumn{9}{|c|}{ Women ( $n$ 1197) } & \multicolumn{11}{|c|}{ Men ( $n$ 974) } \\
\hline & \multicolumn{2}{|c|}{$\begin{array}{c}\text { None } \\
\text { (0 times/week) } \\
(n \text { 158) }\end{array}$} & \multicolumn{2}{|c|}{$\begin{array}{l}\text { Light }(<3 \\
\text { times/week }) \\
\quad(n 489)\end{array}$} & \multicolumn{2}{|c|}{$\begin{array}{c}\text { Moderate }(3-4 \\
\text { times/week }) \\
(n 93)\end{array}$} & \multicolumn{2}{|c|}{$\begin{array}{l}\text { Regular (daily) } \\
\qquad(n 457)\end{array}$} & \multicolumn{2}{|c|}{$P \dagger$} & \multicolumn{2}{|c|}{$\begin{array}{c}\text { None } \\
\text { (0 times/week) } \\
(n \text { 96) }\end{array}$} & \multicolumn{2}{|c|}{$\begin{array}{l}\text { Light }(<3 \\
\text { times/week) } \\
\quad(n 289)\end{array}$} & \multicolumn{2}{|c|}{$\begin{array}{c}\text { Moderate }(3-4 \\
\text { times/week) } \\
(n 88)\end{array}$} & \multicolumn{2}{|c|}{$\begin{array}{l}\text { Regular (daily) } \\
\qquad(n 501)\end{array}$} & \multicolumn{2}{|c|}{$P \dagger$} \\
\hline & Mean & SD & Mean & SD & Mean & SD & Mean & SD & Linear & Quadratic & Mean & SD & Mean & SD & Mean & SD & Mean & SD & Linear & Quadratic \\
\hline $\mathrm{TAG}^{*}(\mathrm{mg} / \mathrm{l})$ & \multirow{2}{*}{\multicolumn{2}{|c|}{1070}} & \multirow{2}{*}{\multicolumn{2}{|c|}{1080}} & \multirow{2}{*}{\multicolumn{2}{|c|}{930}} & \multirow{2}{*}{\multicolumn{2}{|c|}{900}} & $<0.001$ & 0.595 & \multirow{2}{*}{\multicolumn{2}{|c|}{1100}} & \multirow{2}{*}{\multicolumn{2}{|c|}{1020}} & \multirow{2}{*}{\multicolumn{2}{|c|}{970}} & \multirow{2}{*}{\multicolumn{2}{|c|}{940}} & 0.002 & 0.842 \\
\hline Median & & & & & & & & & & & & & & & & & & & & \\
\hline Interquartile range & \multicolumn{2}{|c|}{$740-1590$} & \multicolumn{2}{|c|}{$740-1510$} & \multicolumn{2}{|c|}{$620-1430$} & \multicolumn{2}{|c|}{$660-1310$} & & & \multicolumn{2}{|c|}{$800-1490$} & \multicolumn{2}{|c|}{$700-1500$} & 690 & 470 & 660 & 380 & & \\
\hline Total cholesterol $(\mathrm{mg} / \mathrm{l})$ & 2210 & 400 & 2280 & 410 & 2360 & 380 & 2300 & 360 & 0.044 & 0.029 & 2030 & 400 & 2060 & 360 & 2120 & 360 & 2110 & 380 & 0.011 & 0.616 \\
\hline LDL-C (mg/l) & 1350 & 360 & 1410 & 390 & 1430 & 370 & 1340 & 360 & 0.125 & $<0.001$ & 1310 & 370 & 1320 & 320 & 1350 & 330 & 1330 & 350 & 0.695 & 0.621 \\
\hline HDL-C (mg/l) & 620 & 170 & 640 & 160 & 720 & 190 & 750 & 190 & $<0.001$ & 0.262 & 480 & 110 & 510 & 170 & 520 & 130 & 570 & 150 & $<0.001$ & 0.705 \\
\hline LDL-C:HDL-C & $2 \cdot 4$ & 1.0 & 2.4 & 1.0 & $2 \cdot 2$ & 0.9 & $2 \cdot 0$ & 0.9 & $<0.001$ & 0.068 & $2 \cdot 9$ & $1 \cdot 1$ & $2 \cdot 8$ & 0.9 & $2 \cdot 7$ & $1 \cdot 0$ & 2.5 & 0.9 & $<0.001$ & 0.538 \\
\hline Large HDL (mg/l) & & & & & & & & & $<0.001$ & 0.132 & & & & & & & & & $<0.001$ & 0.336 \\
\hline Median & & & & & & & & & & & & & & & & & & & & \\
\hline Interquartile range & 110 & & & & & & 190 & & & & & & & & & & & & & \\
\hline Intermediate HDL (mg/l) & & & & & & & & & $<0.001$ & 0.019 & & & & & & & & & $<0.001$ & 0.051 \\
\hline $\begin{array}{l}\text { Median } \\
\text { Interquartile range }\end{array}$ & & & & & & & & & & & & & & & & & & & & \\
\hline Interquartie range & & & & & & & & & & & & & & & & & & & & \\
\hline Small HDL (mg/l) & 180 & 60 & 200 & 50 & 210 & 50 & 200 & 60 & 0.278 & $<0.001$ & 190 & 50 & 200 & 50 & 210 & 50 & 200 & 60 & 0.013 & 0.182 \\
\hline$\%$ Large HDL & & & & & & & & & $<0.001$ & 0.214 & & & & & & & & & 0.002 & 0.436 \\
\hline \% Intermediate HDL & & & & & & & & & 0.103 & 0.035 & & & & & & & & & 0.118 & 0.168 \\
\hline$\%$ Small HDL & & & & & & & & & $<0.001$ & 0.002 & & & & & & & & & $<0.001$ & 0.059 \\
\hline HDL size $(n m)$ & & & & & & & & & $<0.001$ & 0.028 & & & & & & & & & $<0.001$ & 0.197 \\
\hline Median & & & & & & & & & & & & & & & & & & & & \\
\hline Interquartile range & 8.8 & & & & & & 8.9 & & & & & & & & & & & & & \\
\hline
\end{tabular}

LDL-C, LDL-cholesterol; HDL-C, HDL-cholesterol.

* Log transformed for analysis.

$\dagger P$ values for one-way ANOVA weighted linear trend or quadratic trend. 


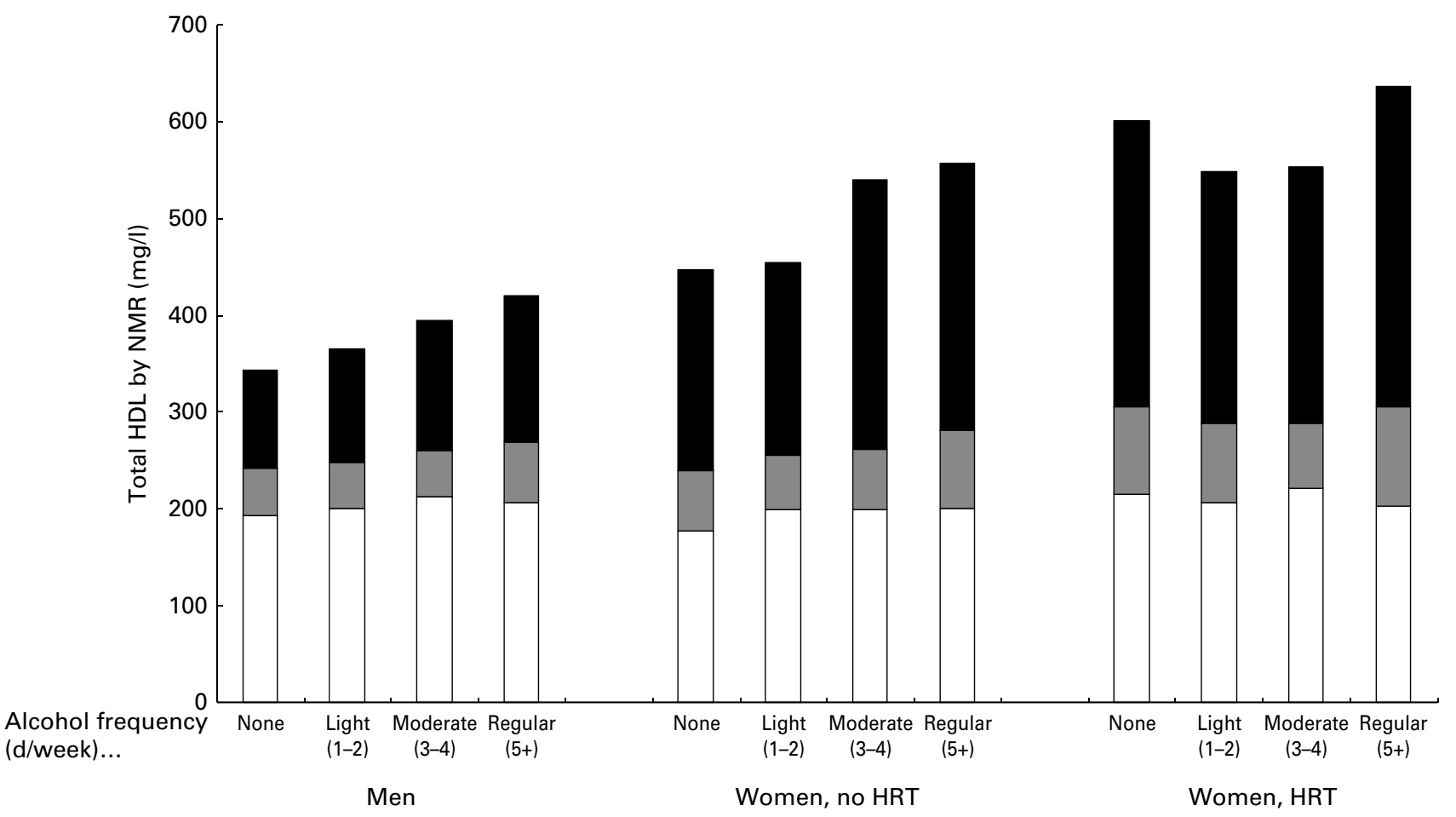

Fig. 1. HDL subclass distribution by sex and hormone replacement therapy (HRT). ( $\square$ ), Large HDL particles; ( $\square$ ), medium HDL particles; ( $\square$ ), small HDL particles.

consumption was associated with higher levels of total HDL and $\mathrm{HDL}_{3}$ cholesterol in African-American participants and greater levels of total $\mathrm{HDL}, \mathrm{HDL}_{2}$ and $\mathrm{HDL}_{3}$ in white participants measured by dextran-sulfate and $\mathrm{Mg}$ precipitation ${ }^{(33)}$. Only one study, the Cardiovascular Health Study of 1850 participants aged 65 years and older, used NMR. They found that alcohol intake was associated with decreased small HDL and increased medium and large HDL measured by $\mathrm{NMR}^{(34)}$.

Assuming that high levels of large HDL are protective, these findings support the hypothesis that alcohol may decrease CVD risk by inducing favourable changes in HDL subclasses. This interpretation is based on the assumption that small HDL contributes to increased cardiovascular risk and large HDL contributes to decreased risk. However, some mechanistic studies suggest that small HDL particles may be anti-inflammatory and thereby decrease CVD risk whereas large HDL particles may be pro-inflammatory and increase risk for recurrent $\mathrm{CVD}^{(19-22,32)}$. Importantly, the latter results are from studies conducted primarily in individuals with prevalent CVD or at high risk for CVD whereas Rancho Bernardo participants are community dwelling and unselected for CVD or CVD risk. Perhaps a pro-inflammatory state such as CVD or consumption of alcohol, which has antiinflammatory effects ${ }^{(35,36)}$, alters the functionality of HDL subclasses. More research is needed to better understand the role of HDL size in CVD risk.

Previous work suggests that alcohol influences HDL through several pathways including: increased production of apo A-1, a HDL precursor ${ }^{(11-13,33)}$; increased muscle ATPbinding cassette, subfamily A (ABCA1) which may be important in recycling preformed HDL through reverse cholesterol transport $^{(37)}$; decreased cholesteryl ester transfer protein
(CETP) ${ }^{(38-41)}$. The blunting of the LDL-C:HDL-C ratio associated with increased alcohol intake in the present study combined with the increased number of large HDL particles is consistent with alcohol-induced decreased CETP activity. Lowered CETP level is associated with increased total and large HDL-P $\mathrm{P}^{(42,43)}$ as well as potent anti-atherosclerotic activity in several studies ${ }^{(38)}$; however, failure of the CETPinhibitor torcetrapib in a clinical trial ${ }^{(44-47)}$ has raised doubts regarding the role of CETP and HDL-C in cardiovascular risk reduction (for a review, see Joy \& $\mathrm{Hegele}^{(48)}$ ). In the Investigation of Lipid Level management to Understand its impact IN ATherosclerotic Events (ILLUMINATE) trial torcetrapib had no impact on atherosclerosis ${ }^{(44-47)}$ and led to elevation in blood pressure, aldosterone levels, and morbidity and mortality. Further analyses suggested that the elevations in blood pressure and aldosterone were probably not due to CETP inhibition, and it may be that these unique side effects contributed to torcetrapib's failure ${ }^{(49)}$. More research is necessary to better understand how alcohol affects CETP inhibition and other pathways to alter lipoprotein distribution and how alcohol-induced lipoprotein changes, which are far more modest than those induced by torcetrapib, affect CVD.

\section{Limitations}

The present study has limitations. The Rancho Bernardo Study cohort is almost entirely white, middle- to upper-middle-class, and older; therefore, these findings may not apply to other age, ethnic and socio-economic groups. Although generalisability is reduced, the homogeneity reduces confounding of socioeconomic status and ethnicity. While it is possible that 
self-reported alcohol intake resulted in over- or underestimating actual intake, relatively high alcohol intakes were freely reported based on a standard questionnaire, probably reflecting normative behaviour for this age and socio-economic group. Although we adjusted for many of the most likely confounders, it is possible that the association between alcohol intake and total HDL and HDL subclasses reflects residual confounding due to unascertained differences between drinkers and non-drinkers. For example, dietary differences could be an important source of confounding. However, there is limited evidence in the literature that common diet items other than alcohol have a meaningful effect on HDLC. The only nutrient proposed to have benefit is $n-3$ fatty acids, largely from fatty fish. Although marine-derived $n-3$ fatty acids have only modest effects on total HDL-C, there is some evidence that they also alter HDL subfractions toward a more favourable, cardioprotective profile (increased $\mathrm{HDL}_{2}$ (large HDL), decreased $\mathrm{HDL}_{3}$ (small HDL) ${ }^{(50,51)}$. The current enthusiasm for consuming fish for health followed the era when the data of the present study were collected. Though fish consumption may affect HDL composition, there is little reason to believe that those who drink more alcohol also consume more fatty fish. Finally, the present study is cross-sectional and therefore causality cannot be assumed, but the strong dose-response association is suggestive.

Other studies have found that LDL subclasses determined by NMR spectroscopy are highly correlated with the subclasses determined by gradient gel electrophoresis ${ }^{(52,53)}$, but the correlation among HDL subclasses has not been adequately evaluated. The NMR-based approach to the lipoprotein subclasses requires ongoing validation.

While our questionnaire did not distinguish regular from binge drinking, binge drinking declines with age and is likely to be low in this cohort where daily drinking was common $^{(54)}$. Because most alcohol consumed in this cohort was wine $(32 \%)$ or mixed drinks $(56 \%)$, not beer $(11 \%)$ or hard liquor $(<1 \%)$, we had limited ability to determine whether beverage type matters. Although wine, especially red wine, is described as a particularly healthy form of alcohol, in epidemiological studies any type of alcohol is usually associated with less $\mathrm{CVD}^{(55,56)}$.

In summary, both alcohol consumption and high levels of HDL-C are associated with a decreased risk of CVD. The present results suggest that one way that alcohol might be cardioprotective is through an increase in overall HDL-C coupled with potentially favourable changes in HDL subclasses, though more research is needed to better understand the role of lipoprotein size in CVD risk as well as how an alcoholrelated lipoprotein profile affects CVD risk and outcomes.

\section{Acknowledgements}

The present study was supported by grants from the Medical Alumni Endowment Fund at the University of North Carolina at Chapel Hill; the National Institute of Diabetes \& Digestive \& Kidney Diseases, a component of the National Institutes of Health (grant no. DK31801); and the National Institutes of Health/National Institute on Aging (grant no. AG07181 and no. AG028507).

We are thankful to the Rancho Bernardo Study participants for their ongoing participation and commitment to the study. 
We also thank Jaclyn (Nikki) Bergstrom for her assistance with statistical analysis and LipoScience, Inc. for NMR spectroscopy lipoprotein analysis of participant blood samples.

N. D. M. was responsible for the conception and design of the study, analysis and interpretation of data, drafting and revising the manuscript, and final approval of the submitted manuscript; G. A. L. was responsible for the conception and design of the study, analysing and interpreting data, writing and revising the manuscript, and the final approval of the manuscript; D. v. M. was responsible for data analysis and interpretation, writing and revising the manuscript, and final approval of the manuscript; S. C. S. Jr was responsible for writing and revising the manuscript, and final approval of the manuscript; E. B.-C. was responsible for the conception and design of the study, analysis and interpretation of data, writing and revising the manuscript, and final approval of the manuscript.

There are no conflicts of interest to disclose.

\section{References}

1. Cannon CP, Braunwald E, McCabe CH, et al. (2004) Intensive versus moderate lipid lowering with statins after acute coronary syndromes. N Engl J Med 350, 1495-1504.

2. LaRosa JC, Grundy SM, Waters DD, et al. (2005) Intensive lipid lowering with atorvastatin in patients with stable coronary disease. $N$ Engl J Med 352, 1425-1435.

3. Expert Panel on Detection, Evaluation, And Treatment of High Blood Cholesterol in Adults (2001) Executive Summary of The Third Report of The National Cholesterol Education Program (NCEP) Expert Panel on Detection, Evaluation, and Treatment of High Blood Cholesterol in Adults (Adult Treatment Panel III). JAMA 285, 2486-2497.

4. Chapman MJ, Assmann G, Fruchart JC, et al. (2004) Raising high-density lipoprotein cholesterol with reduction of cardiovascular risk: the role of nicotinic acid - a position paper developed by the European Consensus Panel on HDL-C. Curr Med Res Opin 20, 1253-1268.

5. Singh IM, Shishehbor MH \& Ansell BJ (2007) High-density lipoprotein as a therapeutic target: a systematic review. JAMA 298, 786-798.

6. O'Keefe JH, Bybee KA \& Lavie CJ (2007) Alcohol and cardiovascular health: the razor-sharp double-edged sword. $J$ Am Coll Cardiol 50, 1009-1014.

7. Criqui MH, Cowan LD, Tyroler HA, et al. (1987) Lipoproteins as mediators for the effects of alcohol consumption and cigarette smoking on cardiovascular mortality: results form the Lipid Research Clinics Follow-up Study. Am J Epidemiol 126, 629-637.

8. Asztalos BF, Cupples LA, Demissie S, et al. (2004) Highdensity lipoprotein subpopulation profile and coronary heart disease prevalence in male participants of the Framingham Offspring Study. Arterioscler Thromb Vasc Biol 24, 2181-2187.

9. Fievet C \& Fruchart JC (1991) HDL heterogeneity and coronary heart disease. Diabetes Metab Rev 7, 155-162.

10. Freedman DS, Otvos JD, Jeyarajah EJ, et al. (1998) Relation of lipoprotein subclasses as measured by proton nuclear magnetic resonance spectroscopy to coronary artery disease. Arterioscler Thromb Vasc Biol 18, 1046-1053.

11. Gaziano JM, Buring JE, Breslow JL, et al. (1993) Moderate alcohol intake, increased levels of high-density lipoprotein and its subfractions, and decreased risk of myocardial infarction. $N$ Engl J Med 329, 1829-1834.

12. Rimm EB \& Moats C (2007) Alcohol and coronary heart disease: drinking patterns and mediators of effect. Ann Epidemiol 17, Suppl. 5, S3.
13. Valmadrid CT, Klein R, Moss SE, et al. (1999) Alcohol intake and the risk of coronary heart disease mortality in persons with older-onset diabetes mellitus. JAMA 282, 239-246.

14. Hattori H, Kujiraoka T, Egashira T, et al. (2004) Association of coronary heart disease with pre- $\beta$-HDL concentrations in Japanese men. Clin Chem 50, 589-595.

15. Miller NE (1987) Associations of high-density lipoprotein subclasses and apolipoproteins with ischemic heart disease and coronary atherosclerosis. Am Heart J 113, 589-597.

16. Yu S, Yarnell JW, Sweetnam P, et al. (2003) High density lipoprotein subfractions and the risk of coronary heart disease: 9-years follow-up in the Caerphilly Study. Atherosclerosis 166, 331-338.

17. Rosenson RS, Otvos JD \& Freedman DS (2002) Relations of lipoprotein subclass levels and low-density lipoprotein size to progression of coronary artery disease in the Pravastatin Limitation of Atherosclerosis in the Coronary Arteries (PLAC-I) trial. Am J Cardiol 90, 89-94.

18. Otvos JD, Collins D, Freedman DS, et al. (2006) Low-density lipoprotein and high-density lipoprotein particle subclasses predict coronary events and are favorably changed by gemfibrozil therapy in the Veterans Affairs High-Density Lipoprotein Intervention Trial. Circulation 113, 1556-1563.

19. Ansell BJ, Fonarow GC \& Fogelman AM (2006) High-density lipoprotein: is it always atheroprotective? Curr Atheroscler Rep 8, 405-411.

20. Ansell BJ, Navab M, Hama S, et al. (2003) Inflammatory/antiinflammatory properties of high-density lipoprotein distinguish patients from control subjects better than high-density lipoprotein cholesterol levels and are favorably affected by simvastatin treatment. Circulation 108, 2751-2756.

21. Navab M, Ananthramaiah GM, Reddy ST, et al. (2004) The oxidation hypothesis of atherogenesis: the role of oxidized phospholipids and HDL. J Lipid Res 45, 993-1007.

22. van der Steeg WA, Holme I, Boekholdt SM, et al. (2008) Highdensity lipoprotein cholesterol, high-density lipoprotein particle size, and apolipoprotein A-I: significance for cardiovascular risk: the IDEAL and EPIC-Norfolk studies. J Am Coll Cardiol 51, 634-642.

23. Otvos JD, Jeyarajah EJ, Bennet DW, et al. (1992) Development of proton NMR spectroscopic method for determining plasma lipoprotein concentrations and subspecies distribution from a single, rapid measurement. Clin Chem 38, 1632-1638.

24. Freedman DS, Otvos JD, Jeyarajah EJ, et al. (2004) Sex and age differences in lipoprotein subclasses measured by nuclear magnetic resonance spectroscopy: the Framingham Study. Clin Chem 50, 1189-1200.

25. Friedewald WT, Levy RI \& Fredrickson DS (1972) Estimation of the concentration of low-density lipoprotein cholesterol in plasma, without use of the preparative ultracentrifuge. Clin Chem 18, 499-502.

26. World Health Organization (1999) Definition, Diagnosis, and Classification of Diabetes Mellitus and its Complications. Part 1: Diagnosis and Classification of Diabetes Mellitus. Geneva: WHO.

27. Mackey RH, Kuller LH, Sutton-Tyrrell K, et al. (2005) Hormone therapy, lipoprotein subclasses, and coronary calcification: the Healthy Women Study. Arch Intern Med 165, 510-515.

28. Penckofer SM, Hackbarth D \& Schwertz DW (2003) Estrogen plus progestin therapy: the cardiovascular risks exceed the benefits. J Cardiovasc Nurs 18, 347-355.

29. Vadlamudi S, MacLean P, Israel RG, et al. (1998) Effects of oral combined hormone replacement therapy on plasma lipids and lipoproteins. Metabolism 47, 1222-1226.

30. Morgan JM, Carey CM, Lincoff A, et al. (2004) The effects of niacin on lipoprotein subclass distribution. Prev Cardiol 7, 182-188. 
31. Williams PT, Vranizan KM, Austin MA, et al. (1993) Associations of age, adiposity, alcohol intake, menstrual status, and estrogen therapy with high-density lipoprotein subclasses. Arterioscler Thromb 13, 1654-1661.

32. Schafer C, Parlesak A, Eckoldt J, et al. (2007) Beyond HDL-cholesterol increase: phospholipid enrichment and shift from $\mathrm{HDL}_{3}$ to $\mathrm{HDL}_{2}$ in alcohol consumers. J Lipid Res 48 $1550-1558$.

33. Volcik KA, Ballantyne CM, Fuchs FD, et al. (2008) Relationship of alcohol consumption and type of alcoholic beverage consumed with plasma lipid levels: differences between whites and African Americans of the ARIC study. Ann Epidemiol 18, 101-107.

34. Mukamal KJ, Mackey RH, Kuller LH, et al. (2007) Alcohol consumption and lipoprotein subclasses in older adults. J Clin Endocrinol Metab 92, 2559-2566.

35. Albert MA, Glynn RJ \& Ridker PM (2003) Alcohol consumption and plasma concentration of C-reactive protein. Circulation 107, 443-447.

36. Sierksma A, van der Gaag MS, Kluft C, et al. (2002) Moderate alcohol consumption reduces plasma $\mathrm{C}$-reactive protein and fibrinogen levels; a randomized, diet-controlled intervention study. Eur J Clin Nutr 56, 1130-1136.

37. Hoang A, Tefft C, Duffy SJ, et al. (2008) ABCA1 expression in humans is associated with physical activity and alcohol consumption. Atherosclerosis 197, 197-203.

38. Forrester JS, Makkar R \& Shah PK (2005) Increasing highdensity lipoprotein cholesterol in dyslipidemia by cholesteryl ester transfer protein inhibition: an update for clinicians. Circulation 111, 1847-1854.

39. Hannuksela M, Marcel YL, Kesaniemi YA, et al. (1992) Reduction in the concentration and activity of plasma cholesteryl ester transfer protein by alcohol. J Lipid Res 33, 737-744.

40. Hannuksela ML, Rantala M, Kesaniemi YA, et al. (1996) Ethanol-induced redistribution of cholesteryl ester transfer protein (CETP) between lipoproteins. Arterioscler Thromb Vasc Biol 16, 213-221.

41. Serdyuk AP, Metelskaya VA, Ozerova IN, et al. (2000) Effects of alcohol on the major steps of reverse cholesterol transport. Biochemistry (Mosc) 65, 1310-1315.

42. Brousseau ME, O'Connor JJ Jr, Ordovas JM, et al. (2002) Cholesteryl ester transfer protein TaqI B2B2 genotype is associated with higher HDL cholesterol levels and lower risk of coronary heart disease end points in men with HDL deficiency: Veterans Affairs HDL Cholesterol Intervention Trial. Arterioscler Thromb Vasc Biol 22, 1148-1154.
43. Ordovas JM, Cupples LA, Corella D, et al. (2000) Association of cholesteryl ester transfer protein-TaqIB polymorphism with variations in lipoprotein subclasses and coronary heart disease risk: The Framingham Study. Arterioscler Thromb Vasc Biol 20, $1323-1329$.

44. Barter PJ, Caulfield M, Eriksson M, et al. (2007) Effects of torcetrapib in patients at high risk for coronary events. $N$ Engl J Med 357, 2109-2122.

45. Bots ML, Visseren FL, Evans GW, et al. (2007) Torcetrapib and carotid intima-media thickness in mixed dyslipidaemia (RADIANCE 2 study): a randomised, double-blind trial. Lancet 370, 153-160.

46. Kastelein JJ, van Leuven SI, Burgess L, et al. (2007) Effect of torcetrapib on carotid atherosclerosis in familial hypercholesterolemia. N Engl J Med 356, 1620-1630.

47. Nissen SE, Tardif JC, Nicholls SJ, et al. (2007) Effect of torcetrapib on the progression of coronary atherosclerosis. $N$ Engl J Med 356, 1304-1316.

48. Joy T \& Hegele RA (2008) Is raising HDL a futile strategy for atheroprotection? Nat Rev Drug Discov 7, 143-155.

49. Rader DJ (2007) Illuminating HDL - is it still a viable therapeutic target? N Engl J Med 357, 2180-2183.

50. Mori TA, Burke V, Puddey IB, et al. (2000) Purified eicosapentaenoic and docosahexaenoic acids have differential effects on serum lipids and lipoproteins, LDL particle size, glucose, and insulin in mildly hyperlipidemic men. Am J Clin Nutr 71, $1085-1094$.

51. Lungershausen YK, Abbey M, Nestel PJ, et al. (1994) Reduction of blood pressure and plasma triglycerides by omega- 3 fatty acids in treated hypertensives. J Hypertens 12, 1041-1045.

52. Blake GJ, Otvos JD, Rifai N, et al. (2002) Low-density lipoprotein particle concentration and size as determined by nuclear magnetic resonance spectroscopy as predictors of cardiovascular disease in women. Circulation 106, 1930-1937.

53. Grundy SM, Vega GL, Otvos JD, et al. (1999) Hepatic lipase influences high density lipoprotein subclass distribution in normotriglyceridemic men: genetic and pharmacological evidence. J Lipid Res 40, 229-234.

54. Naimi TS, Brewer RD, Mokdad A, et al. (2003) Binge drinking among US adults. JAMA 289, 70-75.

55. Mukamal KJ, Conigrave KM, Mittleman MA, et al. (2003) Roles of drinking pattern and type of alcohol consumed in coronary heart disease in men. $N$ Engl J Med 348, 109-118.

56. Mukamal KJ, Jensen MK, Gronbaek M, et al. (2005) Drinking frequency, mediating biomarkers, and risk of myocardial infarction in women and men. Circulation 112, 1406-1413. 